\title{
Gender equality and the effectiveness of primary education in Katosi town council, Mukono district in central Uganda
}

\author{
Moreen Amoding ${ }^{1 *}$, David Mwesigwa ${ }^{2}$ \\ Discipline of Public Administration and Management, Uganda Christian University ${ }^{1}$ \\ Discipline of Public Administration and Management, Lira University, mid-north of Uganda ${ }^{2}$ \\ kedymoryn@gmail.com ${ }^{1 *}$,dmwesigwa@ lirauni.ac.ug ${ }^{2}$
}

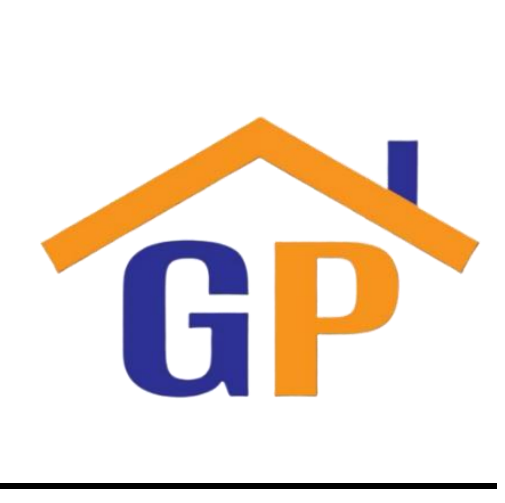

Article History

Received on 22 January 2021

$1^{\text {st }}$ on Revision on 4 February 2021

$2^{\text {nd }}$ Revision on 17 February 2021

Accepted on 18 February 2021

\section{Abstract}

Purpose: This study aimed to assess ways by which Gender Equality affects primary education in Mukono District

Research methodology: This study is a case study that concentrates on a single institute to provide information that can be used in similar businesses to establish the effect of gender equality on primary school. A case study as the research design was preferred because it helps to measure the relationship among variables. A random sampling technique was applied in the study to produce more reliable results.

Results: Results indicate that majority of pupils said that three pupils shared one text book. Also, schools only hire highly skilled teachers that a helping in the accessibility of gender equal skilled teachers that a helping in the primary education.

Limitations: The study covered only one town council in one district local government and so the results may not be generalized across the country or region.

Contribution: The results of this study can be useful to educationists and policy planners.

Keywords: Gender, Gender equality, Primary schools, UPE

How to cite: Amoding, M., \& Mwesigwa, D. (2021). Gender equality and the effectiveness of primary education in Katosi town council, Mukono district in central Uganda. Journal of Social, Humanity, and Education, 1(2), 133-142.

\section{Introduction}

The idea of gender is now part of every economic development agenda. Awareness by international organizations of the need to address gender issues evolved over the past decades. For example, women have started making positive gains in every aspect ranging from socioeconomic to political across nations (Robertson, Lopez-Acevedo \& Savchenko, 2020:295). The bank ordered its programs in 1984 to fix women's problems. The bank published a gender and development policy paper in 1994, reflecting current thinking on this subject. This policy is intended to address structural weaknesses that perpetuate gender inequalities, thus limiting the advisor development program's effectiveness. (Santos, Horta \& Amâncio, 2020). A so-called Gender Action Plan was implemented thirty years after the appointment of a first women development consultant to highlight the relevance of the problem in development strategies and implement the latest smart economics approach. The World Development Report was the first in the 2012 Gender and Development Consultant series (Robertson et al 2020, 2020).

Women have very few opportunities or rights in certain parts of the world with little hope of improving their lives. They are limited in terms of schooling, property ownership, money returns to work, financial resources and decision-making opportunities at family and social level. (Ahmed, Ahmed, Hoque, Majid \& Chhikara, 2019). Country by country, the lack of resources and opportunities open to women is strongly associated with society-wide poverty or lack of development. It is reported that almost all of 
the countries ranked in the top quintile of wealth provide social and economic equality to women; none of those in the lowest quintile does (Sanfelici, 2019). The notion of discrimination of persons in education based on gender differences appears to be resulting from general conditions within the wider human society. These inequalities between men and women, boys and girls in opportunity and assets relate to the societal settings which aid poor academic performance. Consequently, if we must deal with the persistent gender discrimination in key sectors, including education, we need to adopt robust policy frameworks that can help attain that target. Several reforms with the education sector have tended to eradicate gender disproportions to achieve transformed humanity. This strategy is central to elementary education's success, which is open to all school school children. Gender imbalances in the education sector become noticeable at every level ranging from admission to completing a particular cycle. Indeed, similar imbalances have been noticeable even amongst the teachers who deliver vital content at every level of education with several cases where the situation is worse.

In the case of admission at the elementary level, noticeable gender gaps suggest that gender imbalances in accessing education are biased against females and girls. For instance, approximately 104 million children failed to get registered in 2000 , with a proportion of $57 \%$ being girls. As if to make matters even worse, the situation of girls either dropping out or failing to join school was in sub-Saharan African (SSA) region and parts of Asia. Also, gender disproportions tend to be apparent in the rate of school attendance with statistics indicating as high as $85.2 \%$ for boys and $78.3 \%$ for girls in the age bracket of 6-10 years for India over the period 1998-9. The school rate at which a child can remain in school shows an obvious situation against the girl-child for much of Africa (Passinhas \& Proenca, 2020). Worse still, the rates is worse in the region of SSA. The rate at which a child can remain in school is very low in much of Africa where more boys than for girls have prospects of completing the school cycle (UNESCO, 2003). In fact, gender disequilibrium within the primary school teachers is a pointer for gendered consequences in the foundational education cycle. For example, the growth in school enrolment for girls compared to boys and as a percentage of female tutors has remained low as well. A survey report by UNESCO (op cit.) suggests that elementary teachers' bottommost situation appears among nations where gender disproportions are uppermost. This reveals that there is robust 'reminiscent proof' that strategies aimed at realizing parity in gender equilibrium will enhance gender uniformity in the education sector. As a result, the evolution from elementary education to post-elementary education suggests substantial differences across the regions. Nonetheless, a recent study reveals that in approximately 26 countries (with 19 in SSA), no more than $30 \%$ of that age bracket are registered in post-primary education (Prieto-Rodriguez, Sincock \& Blackmore, 2020). Remarkably, nations with enormous differences on boys' side in elementary schooling within SSA bring out the differences in post-elementary schooling. However, too, statistics on post-elementary school drop-out suggest greater variances between boys and girls as the latter have a propensity for plummeting due to financial whys and wherefores, the household ins and outs, as well as prenatal period or parenting.

Several common problems exist in the SSA, which are of concern to women throughout the region. Cultural disparity in gender roles can help to illustrate how gender standards are developed socially by addressing gender issues and gender and the development context in sub Saharan Africa. (Stanziani, Newman Cox \& Coffey, 2020). Many research studies have shown that women in Sub-Saharan Africa are more vulnerable than in any field worldwide. Also, research results from i.e. North Africa, too, has revealed that an African continent impedes women's complete enjoyment of political, social, economic and legal rights even though there have been encouraging developments over recent years. (Bilgin \& Esencan, 2020). Despite a number of positive developments brought about by SAPs, poverty remains widespread in the East African countries. Data reveals that poverty is on the rise in Africa and that women in particular are widespread (Kimengsi, Balgah, Buchenrieder, Silberberger \& Batosor, 2020). Gender inequality in access to and control of a wide range of assets and resources remains inescapable in sub-Saharan Africa.

There has been a determined effort by Uganda's government to further gender equality in development planning and policy. Promotion of gender equality has been emphasized in the Poverty eradication action plan (Cuesta, Biggeri, Hernandez-Licona, Aparicio \& Guillén-Fernández, 2020). The Constitution of Uganda guarantees equality between women and men under the law in political, social 
and cultural life. A number of laws have been revised in line with this constitutional provision; these include the Local Governments Act (Cap 243), the Land Act (Cap 227), the Land Acquisition Act (Cap 226) and the National Agricultural Advisory Services Act. Further, the government formulated the National Gender Policy in 1997 and revised it in 2007 to ensure that all government policies and programmes are consistent with the long- term goal of eliminating gender inequalities. In Mukono district, women prepare meals and also provide some necessities for their homes while the men do a lot of construction. There are quite several cases of domestic violence (232) handled per year. The ratio of literate women to men is $4: 1$. With this on ground; women are very much involved in the district's development (Hennebry, Hari \& Piper, 2019).

\section{Literature review}

A survey of the relevant literature on the effect of gender equality on primary education reveals that inadequate research has been done in this critical area of study. Related research has been carried out by Bekana (2020). The findings in all these studies disclose a positive and significant relationship between the respective variables under study. Much as the research methods used in these studies can be appreciated, the studies did not reveal the effects of gender equality on primary education in developing countries like Uganda which this study seeks to investigate. None of the above studies addresses the context of gender equality and how each dimension affects primary education.

\subsection{Gender equality}

According to Lindqvist, Sendén and Renström (2020), the term gender in terms of economic, social and cultural attributes and opportunities are associated with being male or female. Gender attributes and characteristics, encompassing, inter alia, the roles that men and women play and the expectations placed upon them, vary widely among societies and change over time. Given that gender attributes are socially constructed means that they are also amenable to change in ways that can make a society more just and equitable. Gender equality is the view that men and women should receive equal treatment, and should not be discriminated against based on gender, unless there is a sound biological reason for different treatment (Bekana, 2020). Gender equality is understood as measurable equal representation of women and men but does not suggest that women and men are the same, but that they have equal value and should be accorded equal treatment (Munene \& Wambiya, 2019). The United Nations posits that empowering women is an indispensable tool for advancing development. However, this seems to be distant in Mukono District where a number of men consider empowering women as a threat to their status in the community. So their children will not respect them as fathers since their mothers can look after them. If their women are empowered, marriages will break up and gardens will not be attended to. In effect, several women fear being empowered on the pretext that their husbands will maltreat them and pull back their support to children.

There is robust intercontinental unanimity that gender parity can be enhanced by attaining gender parity in the schooling system. This is the implication of eradicating gender disproportions in elementary and post-elementary levels. However, then again for a number of them, this target has turned out to be one and the same with endeavours to realize girl-child education. Accessible statistics on children who drop out of school corroborates with the need for this line of attack in a number of nations (UNESCO, 2003). Thus, nations have a need to guarantee that schools turn out to be atmospheres where gender parity is universal and dependable through the content covered in the syllabuses that guarantees that gender favouritism and typecasting are detached. Away from this, the core curriculum ought to consider the material and practices that aim to encourage gender parity both within and without the teaching space. Correspondingly, the curriculum for teachers training needs consideration by providing every teacher with apt gender-based awareness and skills necessary in making the classroom gender-responsive in terms of layout, use of learning aids, responsibilities for activities, discipline, language and teacherstudent interaction (CohenMiller, Koo, Collins \& Lewis, 2020). Further, Ministries of Education need to develop mechanisms intended to monitor and evaluate education policy implementation from a gender equality perspective by ensuring that inequality is prevented and its impact is addressed in and through education. According to Ibrahimhakkioğlu (2019), a central element in approaching gender among young people is to challenge boys and girls' traditional gender socialization, which should 
empower girls and women and focus on male identities and address the negative aspects of male socialization. This embraces challenging gender stereotypes, violence, male sexual conduct and issues of reproductive health.

Recent studies suggest that public interventions cannot succeed minus a strong gender component, and young men need openings to brainstorm how gender philosophies and practices impact their conduct and judgment. Further evidence recommends that varied clusters are more constructive than solitary groups seeing that they facilitate adolescents' attention to girls' views. Also, interventions that aim to enhance gender equality at school can ease young women's susceptibility to HIV infection (Joshua, Williams, Benton \& Uhl, 2020). Besides, making sure that the learning atmosphere is safe, near enough to homes by means of simple accommodation as well as public health, positive community support, parental participation and friendly timetables is key. However, there is a belief that educational development leads to faster economic growth, additional prosperity and better income distribution, greater equality of prospects, availability of trained human capital, a decline in population explosion, longer life, better health outcomes, low delinquency, national accord and political stability (Wheeler \& Bach, 2020). Thus, current education concerns the quality as provided in the school, family, and society. Despite the fact that Mukono District has good primary schools that perform better like Bright Academy Mukono and Seeta Junior schools, the quality of education is still low and boys perform better than girls. Therefore, all children in Katosi can access free or cheap quality education to achieve uniformity in education which later transforms into social development.

\subsection{Problem statement}

The gender disparity influences the structure and management of the education system, teachers' activities and behavior, learning material, and curriculum content. Education initiatives cannot fix the gender inequality issues in society. However, education can have a huge effect on the lives of men and women. Education can be critical in transforming attitudes to gender equality as a basic social value. According to Van den Broeck (2020), urban schools excel in academic performance better than rural schools and of these, $61 \%$ of the boys perform better than girls. Haynes (2020) found that boys access bigger space during co-curricular activities like playing games while girls are allocated a few square meters. Statistics from Uganda National Examinations Board revealed that during the year under review (2012), the number of pupils who passed in Grade I was only $1.3 \%$ with the majority passing in Grade II and III at $48.5 \%$ and $20 \%$ respectively. A considerable number (15.6\%) were ungraded suggesting that they failed and yet many were girls. While government has tried to implement SAPs in its education policy through universal primary education, primary schools' performance, especially for girls, continues to decline. Consequently, this study focusses on the effect of gender equality on primary education in Mukono district of central Uganda.

\subsection{Purpose and objectives of the study}

This study aimed to assess the effect of gender equality on primary education in Mukono District. Consequently, three objectives were guided the study, namely: (a) To establish the degree of gender equality in Katosi town council; (b) to establish the effectiveness of primary education in Katosi town council; and (c) to determine the relationship between gender equality and primary education Katosi town council.

\section{Research methodology}

The study took a case study the research intends to concentrate on a single institute to provide information that can be used in similar businesses to establish the effect of gender equality on primary school. The study was carried out in Katosi town council located approximately 27 kilometres (17 mi), by road, southeast of Mukono municipality. The study targeted a population of pupils and teachers in the primary schools in Katosi town council because it is one of the rural-urban areas most affected by gender issues and social mal-development. A random sampling technique was adopted since samples have less errors during data collection, are easy to handle and can easily be generalized to the whole population (Zaman, 2020). The sample size was determined using the table as adopted by Krejcie \& Morgan. Construct validity was conducted to determine whether the instrument addresses the concept as theorized; content validity was established by pre-testing the questionnaires with a selected group. 
Both the degree of gender equality and the effective primary education were analyzed using descriptive statistics, the relationship between gender equality and primary education was determined using chisquare. In contrast, the effect of gender equality on primary education was established using multivariate analysis.

\section{Results and discussion}

\subsection{The degree of gender equality in Katosi town council}

Regarding the degree of gender equality, seven items were presented to respondents, the outcomes were analyzed using means and standard deviations. First, regarding equal access to economic resources, the results revealed moderate accessibility to resources at a mean $(\mu=2.77)$, which is moderate regarding the scale adopted in the research suggesting moderate access to economic resources among both genders. This can be noted from the high standard deviation $(S D=1.467)$, which agrees with the view that access to economic resources in Katosi town council digresses from the mean value. Turning to decision-making among both gender, the findings revealed that there is moderate decision-making among men and women in Katosi town council as several respondents were impartial with equal opportunities for decision-making at a mean $(\mu=3.14)$, which is a moderate mean regarding the scale adopted in this study, suggesting a moderate involvement in decision-making among both men and women in Katosi town council. This result demonstrates, from the standard deviation $(\mathrm{SD}=1.458)$, which suggests how both men and women's involvement in decision-making diverges from the mean value.

The findings indicate that there is a high prospect of owning property among both men and women at $\mu=4.01$, this a high mean value regarding the scale used in the study. This suggests a high prospect of property ownership among both genders with a standard deviation $(S D=1.03)$ demonstrating how property ownership in Katosi town council deviates from the mean value. The high level of agreement could be because the National gender policy of 2007 is a big push in regard to economic liberation between men and women in Katosi town council. Further, the findings demonstrate a moderate degree regarding ability of both genders to choose a school where their children can study from as long as one can afford at a mean $(\mu=3.17)$, which is a moderate mean suggesting that ability to choose a school amongst the two sexes is still moderate in Katosi town council. The high standard deviation $(S D=1.99)$ shows how choice of a school deviates from the mean suggesting a moderate choice between the genders in Katosi.

The study reveals that taking part in the local governance at every level, was low (aggregate $\mu=1.94$, $\mathrm{SD}=1.16)$ although the policy allows both to compete for any available position. Majority of the respondents $(88 / 74.5 \%)$ revealed that it was not easy for women to compete against men save for those positions reserved for women alone. Nonetheless, many respondents $(52 / 44.6 \%)$ revealed that some women had started gaining confidence in competing with men at the higher local government although with very success. Results further show that respondents agreed $(\mu=3.57 ; \mathrm{SD}=1.34)$ that both can form associations and pursue their group's goals and objectives. Micro-finance's existing policy encourages women (and men) to form groups in the form savings and credit cooperative organizations (SACCOs). They can save starting with any amount thus allowing them to access finance with less conditionalities than traditional commercial banks. It might also be due to increased sensitization offered by the intermediary micro-finance institutions that have spread their wings across the entire country. Finally, results reveal a high prospect of both men and women being equal before the law $(\mu=3.49 ; \mathrm{SD}=1.30)$ in Katosi town council. In general, gender equality in Katosi town council is moderate and existent as illustrated by the overall mean $(\mu=3.07)$ suggesting a high mean as per the scale. This is also supported by the results of the standard deviations $(\mathrm{SD}=1.426)$, which were high, suggesting that gender equality deviates from the mean implying moderate gender equality in the area of study.

4.2. The effectiveness of primary education in Katosi town council

Respondents were presented with an array of the effectiveness of primary education and asked to indicate their opinion. As a result, $70 \%$ of the respondents agreed that an effective primary education is a wealth source to the community while $20 \%$ disagreed with the Idea. The majority of respondents $(62.9 \%)$ in all groups acknowledged that effective primary education improves skills whereas $25.1 \%$ 
do not perceive effective primary education to be of any influence to skill improvement on primary education. These responses did observe any relations between respondents of various skill improvements for sending their children to school. Almost all the respondents $80 \%$ agreed with this issue that both rich and poor children have access to quality education from accessing quality education in primary while only $3.1 \%$ disagreed with the ideology. The researchers note that effective primary education enhances poor children's access to education and other children. Possibly, that is why concepts like the Education for All (EFA) and its offspring, universal primary education were initiated. But the researchers agree with the respondents that because of the perceived added costs of health related problems, the problem is relatively deeper when the poor are involved. And there does not seem to be any reduction strategies being mainstreamed in all development initiatives through affirmative action to the children in Katosi town council.

Regarding rural and urban areas, $61.7 \%$ of the respondents, teachers and parents/caregivers agreed that effective primary education is essential both in the villages and towns whereas $21.1 \%$ disagreed. The fact that $77.1 \%$ of the respondents agreed that effective primary education in Katosi schools desires additional support in funding from government and partners. The researchers identified lack of enough funding affects effective primary education. Since the majority acknowledged that they lack enough funding in their school, the children do not get effective primary education in primary schools in Katosi. The respondents agreed that there are hardly enough schools in Katosi town council that provide effective primary education as noted by $51.7 \%$ while $33.7 \%$ were in disagreement on the issue. This is because heavy private school investments have risen in the area because of population explosion in the area that serves as the market and, hence, leads to access to alternative outlets to effective primary education.

More so, most of the respondents agreed that access to effective primary education is determined by parents' income as noted by $71.3 \%$ whereas $25 \%$ disagreed. This suggests that for any child to access quality education in primary education, the parent or guardian should have an income source that can facilitate all the child's school requirements. $67 \%$ of the respondents agreed that they have social clubs like English clubs, debate clubs, while 37\% disagreed. Consequently, it was concluded that a number of students in primary schools in Katosi council access quality education. Students revealed that they attend debate clubs, music, dance, and drama, as $79 \%$ noted, with only $21 \%$ disagreed with the issue. This reveals that many primary schools in Katosi town desire quality education to be accessed by the students. This was supplemented with the view that teachers set continuous assessment materials from their own schools.

Respondents were also presented with an array of school-related access to scholastic materials and asked to indicate whether access to scholastic materials hindered access to quality primary education. $80 \%$ of respondents cited that the parents easily provide their children with books, pens and pencils with ease as incomprehensive and thus affecting the access of gender equality to all-inclusive education whereas only $10 \%$ disagreed with the statement. However, teachers disagreed and most of the parents had nothing to say. In other words they did not know either way. When the respondents were asked to give their reasons for their answers the non-response was 1 percent. The responses were found to be irrelevant to issues like: how does the parent take care of needs for boys and girls children or those with learning difficulties.

Most of the respondents and teachers agreed that the school provides its students with scholastic materials like text books, exercise books, computers as noted by $61 \%$ while $36.9 \%$. This phenomena is directly related to good macro policy on these materials and the low costs on the open market. The critical availability of scholastic materials means the inclusive education is in place. This was also supported by the $60.2 \%$ respondents who acknowledged that the government supports primary schools by providing enough scholastic materials in form of textbooks while $34.4 \%$ were in disagreement. Most of the respondent groups $79.9 \%$ added that access to books, pens, pencils, and computer laboratory enhances education quality whereas $19.9 \%$ disagreed. Furthermore, $70.1 \%$ respondents agreed that pupils who have access to scholastic materials perform better than those without while $20 \%$ disagreed. The findings reveal that $60.3 \%$ respondents agreed that computers are a way of accessing quality 
education whereas $34.2 \%$. This implies that the existence of technology had major influence on accessing quality education. The study also indicated that $61.4 \%$ respondents agree with the issues that the school management encourages pupils to use the library to enhance their academic performance whereas $32.3 \%$ disagreed. The study findings reveal that availability of library and democratic school management of Katosi schools has led to accessibility of quality primary education. Respondents supplemented that the access to the school library improves pupils' reading skills as noted by $77.1 \%$ though $15.9 \%$ disagreed. The findings imply that availability of scholastic materials have made it possible for children equally access quality primary education in Katosi town.

The findings reveals that majority (82\%) pupils said that they shared text books in class while $18 \%$ of pupils said they did not share. Data suggests that majority (59.2\%) of pupils said that three pupils shared one text book. Majority (69\%) pupils said that there were enough while $31 \%$ of pupils said they did not get enough meals. The study further sought to investigate whether the school had school uniforms and shoes. Majority (60\%) pupils said they had school uniforms and shoes while $38 \%$ said they did not have school uniforms and shoes. The findings suggest that $23.1 \%$ of head teachers indicated that textbooks and exercise books were inadequate, $46.1 \%$ indicated that teachers were inadequate. $30.8 \%$ of head teachers reported that school furniture were inadequate. Data further suggests that $38.5 \%$ disagreed that class rooms and toilets were adequate, affecting quality education in the schools. $63.3 \%$ agreed, $31.7 \%$ disagreed while $5 \%$ were neutral. This suggests that schools hire skilled teachers to help in the accessibility of gender-equal skilled teachers that helping in the primary education. On whether teachers have access to free bursaries for their children, it was noted that $29.4 \%$ of the respondents disagreed, $61.7 \%$ agreed and $1.6 \%$ were undecided. By interpretation, there was no accessibility to free bursaries for teachers' children which lead to low teaching motives and poor quality education. On whether as a result of access to skilled teachers, students attain outstanding academic performance, it was noted that $77.1 \%$ agreed while the remaining $15.9 \%$ disagreed. This meant that on the whole, there were adequate written teaching skills that are helping in the accessibility of quality education in Katosi schools which impacts positively on academic performance. Generally, $70 \%$ of the respondents agreed on the statement whether access to skilled teachers has led to the development in the co-curricular activities like music, dance and drama, only $36.9 \%$ agreed while $1.1 \%$ was undecided. On whether individual student strengths have been developed as a result of access to skilled teachers, it was noted that $60 \%$ of the respondents agreed, $20 \%$ disagreed and 1\% were undecided. By interpretation, the students' strengths affect the accessibility of quality education. The findings reveals that majority (70\%) pupils said that their teachers begin class on time while $20 \%$ of pupils said they don't begin class on time. Data suggests that most pupils (59\%) said that they trust our teachers when we have a problem. The study further sought from the pupils whether they learn a lot from our teachers. From the study, most 65(65\%) pupils said that they learn a lot from our teachers while $20 \%$ of pupils said they did not learn a lot from our teachers.

\subsection{The relationship between gender equality and primary education in Katosi town council}

Objective three sought to determine the relationship between gender equality and primary education in Katosi town council. Using the Pearson correlation analysis, results suggest a positive and moderate significant relationship between gender equality and primary education $(r=0.693, p=0.000)$. These results reveal that if the degree of gender equality is enhanced, the effectiveness of primary education is moderately improved. This might be attributable to the equal opportunities accessible to both genders. Further analysis to determine the relationship level using the coefficient of determination $(\mathrm{r} 2=0.479 \mathrm{x} 100)$ suggests that gender equality contributes $47.9 \%$ to primary education's effectiveness. The residual $52.1 \%$ might be resulting from additional elements which were not investigated in this study but can be examined as the effectiveness of primary education is not absolutely dependent on gender equality. Consequently, the notion that there is no significant relationship between gender equality and the effectiveness of primary education in Katosi town council was rejected since the pvalue of 0.000 was less than 0.05 (less of significance) and an alternative hypothesis was accepted. 


\section{Discussion}

Bannink, Nalugya and Van Hove (2020) agree that Uganda uses a standard core curriculum that is a mere transmission of knowledge rather than one framed in developing understanding of the child and growth of critical awareness. Datzberger and Donovan (2020) also stress the need for a comprehensive curriculum: basic learning needs and a common curriculum. Schenk, Tun, Sheehy, et al (2020) also noted that the current curriculum does not serve the needs of the disabled. The lack of enough SNE teachers has predetermined that lack the specialized care they need. This concurs with Sheehy, Kasule and Chamberlain (2019) in their study of pupils with specials needs in ordinary schools, who reported that teachers working with ordinary schools lacked competence to educate pupils with special educational needs. Likewise, Tusiime, Johannesen and Gudmundsdottir (2020) found that teachers lacked special approaches and methods to facilitate learning in integration. The study found one exception the phenomenon mentioned in the previous paragraph. Furthermore, research suggests that there is an important link between student social development and student academic development. Children's academic skill development and social skill development are often closely related (Oluwafemi, Bibire, Mebu, Dung \& Aderibigbe, 2020; Skoura-Kirk, Brown \& Mikelyte, 2020). A study by Deng, Patwardhan, Rudasill, Trainin, Wessels, Torquati and Coplan (2020) has revealed that social actions, including values related to gender, predict academic achievement.

\section{Conclusion}

The notion of all-embracing schooling suggests being friendly to every child regardless, devoid of favouritism, into fixed or normal schools. Certainly, it is an emphasis of developing such as atmosphere that is receptive to the divergent growth abilities, necessities, and capabilities of every child minus gender disproportion. It is an additional provision for gender on distinct requirements and encouraging a child's general growth in an ideal situation. It necessitates attention to the variances as well as range of different physical appearance and desires. This has to consider a concern to the total set-up, core curriculum and teaching space, aids for education and expansion of the workforce. All-encompassing schooling suggests that schooling is concerned with gaining awareness to live and study with each other. Formal schools with an all-encompassing alignment are the most successful approaches to fight bigoted opinions, build friendly societies, build an all-encompassing humanity, and realise education for all. Scarcity among families impedes attaining all-embracing schooling services. Despite the fact that "The government of Uganda endorsed education for All", the real execution is a long way from anticipated. The true number of girls in primary education is insignificant when likened to the percentage of girls within the school age-bracket.

\section{Acknowledgement}

The authors do appreciate the contribution of every respondent who participated in this study and the officials in the department of education of Mukono district.

\section{References}

Ahmed, J.U., Ahmed, A., Hoque, M.T., Majid, M.A., and Chhikara, R. (2019). Women entrepreneurs' fast food business: a case study on challenging social prejudice through entrepreneurship. Small Enterprise Research, 26(3), 307-19.

Bannink, F., Nalugya, R., and Van Hove, G. (2020). 'They give him a chance' - parents' perspectives on disability and inclusive primary education in Uganda. International journal of Disability, Development and Education, 67(4), 357-75. Doi: 10.1080/1034912X.2019.1593326.

Bekana, D.M. (2020). Policies of gender equality in Ethiopia: the transformative perspective. International Journal of Public Administration, 43(4), 312-25. Doi: 10.1080/01900692.2019.1628060.

Bilgin, Z., and Esencan, T.Y. (2020). Perception pf physical exercise in Turkish pregnant women and affecting factors. European Journal of Physiotherapy. Doi: 10.1080/21679169.2020.1790656.

CohenMiller, A.S., Koo, S., Collins, N., and Lewis, J.L. (2020). EXPOsing gender in science: a visual analysis with lesson for gender awareness and science diplomacy. Gender, Technology and Development, 24(2), 215-35. Doi: 10.1080/09718524.2019.1695519.

Cuesta, J., Biggeri, M., Hernadez-Licona, G., Aparicio, R., and Guillén-Fernandez, Y. (2020). The political economy of multidimensional child poverty measurement: a comparative analysis of 
Mexico and Uganda. Oxford Development Studies, 48(2), 117-34. Doi: 10.1080/13600818.2020.1739261.

Datsberger, S., and Donovan, O. (2020). Silencing the past in Ugandan schools: the role of education in reconciliation processes. Peacebuilding, 8(1), 118-34. Doi: 10.1080/21647259.2018.1517963.

Deng, Q., Patwardhan, I., Rudasill, K., Trainin, G., Wessels, S., Torquati, J., and Coplan, R.J. (2020). Shy and outgoing preservice teachers and their responses to hypothetical problem behaviours in the classroom. Educational Psychology. Doi: 10.1080/01443410.2020.1718613.

Haynes, P. (2020). The impact of home-based educational multi-correlates on academic achievement: an analysis of gender discrepancies in Rwanda. International Journal of Inclusive Education, 24(5), 561-77. Doi: 10.1080/13603116.2018.1466929.

Hennebry, J., Hari, K.C., Piper, N. (2019). Not without them: realizing the sustainable development goals for women migrant workers. Journal of Ethnic and Migration Studies, 45(14), 2621-37. Doi: 10.1080/1369183X.2018.1456775.

Ibrahimhakkioğlu, F. (2019). A feminist genealogy of the lived body? Rethinking the gendered body as a site of excess and indeterminacy. Journal of The British Society for Phenomenology, 50(4), 324-36. Doi: 10.1080/00071773.2019.1610830.

Joshua, T.G., Williams, W.O., Benton, S., and Uhl, G. (2020). Evaluation of an HIV prevention intervention for women living with HIV, AIDS. Care, 32(7), 835-42. Doi: 10.1080/09540121.2019.1659910.

Kimengsi, J.N., Balgah, R.A., Buchenrieder, G., Silberberger, M., and Batosor, H.P. (2020). An empirical analysis of credit-financed agribusiness investments and income poverty dynamics of rural women in Cameroon. Community Development, 51(1), 72-89. Doi:10.1080/15575330.2020.1716031.

Lindqvist, A., Senden, M.G., and Renstrom, E.A. (2020). What is gender, anyway: a review of the options for operationalizing gender? Psychology \& sexuality, Doi: 10.1080/19419899.2020.1729844.

Munene, I.I., and Wambiya, P. (2019). Bridging the gender gap through gender difference: aiding patriarchy in South Sudan education reconstruction. Africa Education Review, 16(5), 86-101. Doi: 10.1080/18146627.2018.1429052.

Oluwafemi, O.O., Bibire, A.H., Mebu, V.A., Dung, P.H., and Aderibigbe, J.K. (2020). Conditional indirect effects of gender and school on internet use of academic activities and social-moral development among secondary school students in Nigeria. Cogent Social Sciences, 6:1, Doi: $10.1080 / 23311886.2020 .1748478$.

Passinhas, J., and Proenca, I. (2020). Measuring the gender disparities in unemployment dynamics during the recession: evidence from Portugal. Applied Economics, 52(6), 623-36. .

Prieto-Rodriguez, E., Sincock, K., and Blackmore, K. (2020). STEM initiatives matter: results from a systematic review of secondary school interventions for girls. International Journal of Science Education, 42(7), 1144-61.

Robertson, R., Lopez-Acevedo, G., and Savchenko, Y. (2020). Globalization and the gender earnings gap: evidence from Sri Lanka and Cambodia. The Journal of Development studies, 56(2), 295-313.

Sanfelici, M. (2019). Diversity and equality in social work: a qualitative study in Italy. European Journal of Social Work. Doi: 10.1080/13691457.2019.1646215.

Santos, J.O., Horta, H., and Amâncio, L. (2020). Research agendas of female and male academics: a new perspective on gender disparities in academia. Gender and Education. Doi: 10.1080/09540253.2020.1792844.

Schenk, K.D., Tun, W., Shhehy, M., Okal, J., Kuffour, E., Moono, G., Mutale, F., Kyeremaa, R., Ngirabakunzi, E., AMayeiwe, U., and Leclerc-Madlala, S. (2020). Even the fowl has feelings: access to HIV information and services among persons with disabilities in Ghana, Uganda, and Zambia. Disability and Rehabilitation, 42(3), 335-48. Doi: 10.1080/09638288.2018.1498138.

Sheehy, K., Kasule, G.W., and Chamberlain, L. (2019). Ugandan teachers epistemological beliefs and child-led research: implications for developing inclusive educational practice. International Journal of Disability, Development and Education. Doi: 10.1080/1034912X.2019.1699647. 
Skoura-Kirk, E., Brown, S., and Mikelyte, R. (2020). Playing its part: an evaluation of professional skill development through service use-led role-plays for social work students. Social Work Education. Doi: $10.1080 / 02615479.2020 .1764521$.

Stanziani, M., Newman, A.K., Cox, J., and Coffey, C.A. (2020). Role call: sex, gender roles, and intimate partner violence. Psychology, Crime \& Law, 26(3), 208-25. Doi: 10.1080/1068316X.2019.1652746.

Tusiime, W.E., Johannesen, M., and Gudmundsdottir, G.B. (2020). Teaching art and design in a digital age: challenges facing Ugandan teacher educators. Journal of Vocational Education \& Training. Doi: $10.1080 / 13636820.2020 .1786439$.

UNESCO. (2003). Gender and education for all. The leap to equality. EFA Global Monitoring Report. 2003/4. UNESCO. Paris.

Van den Broeck, G. (2020). Women's employment and family planning in rural Uganda. Women \& Health, 60(5), 517-33. Doi: 10.1080/03630242.2019.1671948.

Wheeler, L.B., and Bach, D. (2020). Understanding the impact of educational development interventions on classroom instruction and student success. International Journal for Academic Development. Doi: 10.1080/1360144X.2020.1777555.

Zaman, T. (2020). An efficient exponential estimator of the mean under stratified random sampling. Mathematical Population Studies. Doi: 10.1080/08898480.2020.1767420. 